\title{
Sürdürülebilir Bir Çevre İçin Karbon Ayak izi Tespiti: MAKÜ Bucak Sağlık Yüksekokulu Örneği
}

\author{
Kazım KUMAŞ ${ }^{1}$, Ali AKYÜZ ${ }^{1}$, Muhammad ZAMAN ${ }^{2}$, Afşin GÜNGÖR ${ }^{3 *}$ \\ ${ }^{1}$ Burdur Mehmet Akif Ersoy Üniversitesi, Bucak Emin Gülmez TBMYO, 15300, Burdur /TÜRKIYE \\ ${ }^{2}$ Pakistan Institute of Engineering \& Applied Sciences, Department of Chemical Engineering, Islamabad/Pakistan, \\ ${ }^{* 3}$ Burdur Mehmet Akif Ersoy Üniversitesi, Teknoloji Fakültesi, 15300, Burdur /TÜRKIYYE \\ kkumas@mehmetakif.edu.tr, aakyuz@mehmetakif.edu.tr, zaman@ pieas.edu.pk, afsingungor@hotmail.com
}

Received/Geliş: 12.09 .2018

Accepted/Kabul: 13.11 .2018

\begin{abstract}
Öz: Dünyada gelişmiş ve gelişmekte olan ülkelerin en önemli gündem maddelerinin başında sera gazı salınımları gelmektedir. Sanayi devriminin başlaması ile doğal iklim değişimleri yaşanmış ve buna ilave olarak insan faaliyetlerinin de iklimi etkilediği yepyeni bir döneme girilmiştir. Dünyada küresel 1sınma ve iklim değişikliği tehdidine karşı düşük karbonlu ekonomiye geçmeye yönelik adımlar atılmakta ve çalışmalar yapılmaktadır. Küresel 1sınmaya doğrudan etki eden $\mathrm{CO}_{2}$ gazının hesaplanabilmesi yapılan çalışmalarda karbon ayak izi kavramı ortaya çıkarılmıştır. Atmosferdeki $\mathrm{CO}_{2}$ miktarının artması ile birlikte araştırmacılar farklı alanlarda karbon ayak izi hesaplama çalışmalarına yönelmişlerdir. Bu çalı̧̧mada Burdur Mehmet Akif Ersoy Üniversitesi Bucak Sağlık Yüksekokuluna ait karbon ayak izi hesabı yapılmıştır. Karbon ayak izi hesabı için Defra Annex hesaplama kriterleri kullanmış ve yıllık karbon ayak izi miktarı tespit edilmiştir. Karbon ayak izi tespitinde toplam elektrik enerjisi tüketimi, ısınma değerleri, personelin ve öğrencilerin günlük ulaşım değerleri, personelin kullandığı araçların yakıt türleri gibi veriler göz önünde bulundurulmuştur. Çalışma sonucunda karbon salınımı miktarının en fazla doğalgazdan, en az ise benzinli araçlardan kaynaklandığı tespit edilmiştir.
\end{abstract}

Anahtar kelimeler: Karbon ayak izi, sera gazı salınımı, iklim değişikliği, küresel ısınma

\section{Carbon Footprint Determination for a Sustainable Environment: MAKÜ Bucak School of Health Example}

\begin{abstract}
Greenhouse gas emissions are at the forefront of the most important agenda items of developed and developing countries in the world. With the beginning of the industrial revolution, natural climate changes have taken place, and in addition, a new round of human activity has also affected the climate. For the danger of global warming and climate change have been taking steps towards the transition to low carbon economy towards. Calculation of the $\mathrm{CO}_{2}$ gas directly affecting global warming has led to the concept of carbon footprint. With the increase in the amount of $\mathrm{CO}_{2}$ in the atmosphere, researchers turned to carbon footprint calculations in different areas. In this study, Burdur Mehmet Akif Ersoy University Bucak School of Health's carbon footprint was calculated. For the carbon footprint calculation, Defra Annex calculation criteria were used and annual carbon footprint quantities have been determined. In determining the carbon footprint, data such as total electricity energy consumption, heating values, daily transportation values of personnel and students, fuel types of the vehicles belonging to the personnel used were considered. As a result of the study, it was found that the amount of carbon emission was mostly caused by natural gas and the least by gasoline vehicles.
\end{abstract}

Keywords: Carbon footprint, greenhouse gas emissions, climate change, global warming. 


\section{Giriş}

Dünyada üretim ve tüketimin artması, sanayi sektörünün hızla gelişmesi kentleşme ve çevre sorunlarını arttırmaktadır. Doğal yapının bozulması, iklim değişikliği, çölleşme ve bazı biyolojik türlerin giderek azalması ciddi tehlike oluşturmaktadır [1].

Fosil yakıtların kullanımı ile ortaya çıkan sera gazları, toprak ve arazinin düzensiz kullanımı iklim değişikliğine neden olan etkenlerin başında gelmektedir ve orman alanlarının azaltılması kullanımı karbon tutma potansiyelini azaltmaktadır. Yirminci yüzyılın ikinci yarısı ile birlikte sanayileşme, enerji tüketimi vb. durumlardan kaynaklanan küresel 1sınma etkisini göstermiş, önlem alınmazsa daha sonraki dönemlerde de etkisinin süreceği ve bu etkinin telafisi olmayan bir durum getireceği belirtilmiştir. Fosil yakıtların bilinçsiz ve verimsizce kullanılması küresel 1sınmanın kaynağı $\mathrm{CO}_{2}$ başta olmak üzere atmosferdeki sera gazlarını artışına sebep olmaktadır. Ülkeler sera gazı salınımlarını azaltma amacına yönelik hedef koyamaması ve gerekli alt yapıyı hazırlayamaması sebebiyle bir sözleşmeye gerek duyulmuş ve 2005 yılında yürürlüğe giren Kyoto Protokolü ile bu durum giderilmiştir. Protokol kapsamında çeşitli mekanizmalar oluşturulmuştur [2]. Tüm bu ifade edilen sorun ve öneriler, yaklaşımlar, oluşturulan mekanizmalar; karbon salınımını azaltmaya yönelik ülkelere, kurum ve kuruluşlara, yatırımcılara, üreticilere farkındalık oluşturmuştur ve karbon ayak izini belirleme çalışmaları hız kazanmıştır [3].

Ülkemizde, Avrupa Birliği uyum süreci kapsamında sera gazı salınımı takibi hakkında yönetmelik 2014 yılında yürürlüğe girmiştir. Üretim ve tüketim safhasında gerçekleşen $\mathrm{CO}_{2}$ gazının atmosfere etkisinin, üretimin her aşamasında hesaplanması gelişmekte olan ülkemizde etraflıca değerlendirilmelidir [4].

Letete vd., (2011) yaptıkları çalışmada Cape Town Üniversitesinin 2007 yılı için karbon ayak izini hesaplamışlardır. Hesaplamada kampüsün enerji tüketimi, ulaşım, mallar ve katkı hizmetleri gibi parametreler kullanılmıştır. 2007 yılına ait üniversitenin karbon ayak izi miktarını 83400 tCO $_{2} \mathrm{e}$ olduğunu ve bu miktarın \%80'nin elektrik tüketiminden kaynaklandığını tespit etmişlerdir. Ayrıca öğrenci başına düşen yıllık salınım değerlerini farklı üniversite değerleri ile karşılaştırmışlardır [5]. Aroonsrimorakot et al., (2013) yaptıkları çalışmada Mahidol Üniversitesi Çevre ve Kaynak Araştırmaları Fakültesinin karbon ayak izini hesaplamışlardır. Karbon ayak izini hesabında elektrik ve su tüketimi, atık su ve çöp miktarı, yakıt miktarı vb. parametreleri kullanmışlardır. Sonuç olarak fakültenin karbon ayak izi $1.091 .85 \mathrm{tCO}_{2} \mathrm{e}$ olarak hesaplamış, salınımın en fazla elektrik tüketiminden oluştuğunu ve bunu katı atıkların izlediğini tespit etmişlerdir [6]. Turanlı (2015) yaptığı çalışmada Orta Doğu Teknik Üniversitesinin 2000-2014 yılları arasındaki karbon ayak izini belirlemiştir. Hesaplamada ulaşım, elektrik, doğal gaz ve gıda tüketimi gibi salınım gerçekleştiren parametreleri kullanmıştır. 2014 yılına ait $\mathrm{CO}_{2}$ salınım yüzdelik oranlarına bakıldığında elektrik tüketiminin \%40, ulaşımın \%31, doğal gaz tüketiminin \% 25 ve beslenme \% 4'olduğu tespit etmiştir [7].Sreng and Yiğit (2017) yaptıkları çalışmada, Sakarya Üniversitesi Esentepe kampüsünün 2015 yılına ait karbon ayak izi hesabını yapmışlardır. Hesaplamada (IPCC) Tier 1 metodu, (WRI) ve (WBCSD)'nın sınır belirleme metotlarını kullanmışlardır. Sonuç olarak Esentepe kampüsünün karbon ayak izini 12,330.73 $\mathrm{tCO}_{2} \mathrm{e}$ olarak tespit etmişlerdir. Bu miktarın oluşmasında en büyük payın elektrik tüketiminden oluştuğu bunu sırasıyla öğrenci ve çalışanlardan kaynaklı salınım miktarları takip ettiğini ifade etmişlerdir [8]. Binboğa ve Ünal (2018), yaptıkları çalışmada Manisa Celal Bayar Üniversitesinin karbon ayak izini hesaplamışlardır. Hesaplamada birincil karbon ayak izi IPCC Modeli Tier 1 yaklaşımını kullanmış ve 2016 yılına ait karbon ayak izi miktarını 8.953,906 $\mathrm{tCO}_{2} \mathrm{e}$ olarak tespit etmişlerdir. Bu salınım değerinin en fazla elektrik tüketiminden, en az ise benzin tüketiminden kaynaklı olduğunu ifade etmişlerdir [9].

Karbon ayak izi hesabı, bir kişinin bir yıl içerisinde doğa ortamına saldığı $\mathrm{CO}_{2}$ miktarının belirlenmesi ile bulunur. Ulaşım, ısınma, yeme, içme vb. aktiviteler ile üretilen ve tüketilen ürünler 
sonucunda oluşan karbon miktarı karbon ayak izini belirlemektedir. Kişilerin küresel 1sınmadaki payının ölçüsünü karbon ayak izi belirler. Bir başka ifade ile bir karbon ayak izi kişinin, kurumların veya herhangi bir üründen kaynaklı olarak doğaya bırakılan sera gazlarının genel toplam içindeki oranıdır. Karbon ayak izi hesabı, araçlarla kat edilen toplam yol, 1sıtma amaçlı kullanılan enerji miktarı vb. birçok parametreyi içerisine almaktadır. Bu bakımdan karbonun birincil ve ikincil izleri belirlenirken dikkat edilmelidir. Karbon ayak izi doğrudan (birincil) ve dolaylı (ikincil) olmak üzere iki kısımdan meydana gelmektedir. Evsel enerji tüketimi, ulaşım, fosil yakıt kullanımı ile meydana gelebilecek $\mathrm{CO}_{2}$ salınımları belirlemede birincil ayak izi, tüm yaşam boyunca kullandığımız ürünlerin imalatı ve son olarak bozulmasına kadar atmosfere salınan $\mathrm{CO}_{2}$ 'yi belirlemede ise ikincil ayak izi kullanılır [10]. Başlıca sera gazı kaynakları Şekil 1'de verilmiştir [2].

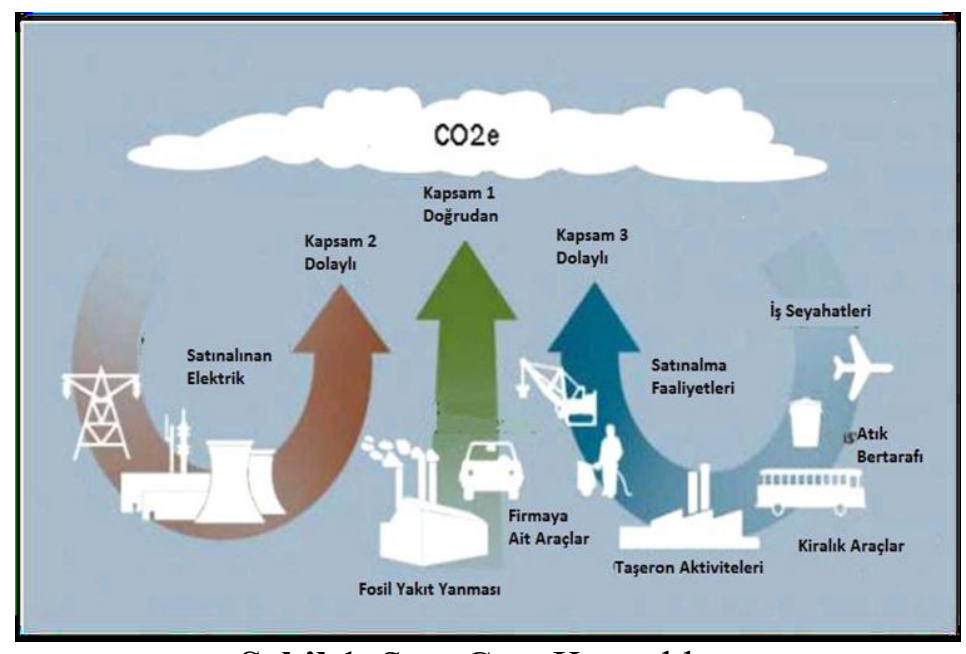

Şekil 1. Sera Gazı Kaynakları

Bu çalışmada Burdur Mehmet Akif Ersoy Üniversitesi Bucak Sağlık Yüksekokulunun karbon ayak izi hesabı Defra-Annex kriterleri kullanılarak yapılmıştır. Karbon ayak izi hesabında yüksekokulun toplam elektrik enerjisi tüketimi, ısınma amaçlı kullanılan yakıt değerleri, personelin ve öğrencilerin günlük ulaşım değerleri, personelin kullandığı araçların yakıt türleri gibi parametre değerleri kullanılmıştır.

\section{Materyal ve Metot}

Burdur Mehmet Akif Ersoy Üniversitesi Bucak Sağlık Yüksekokulunda 17 akademik personel 6 idari personel ve 357 öğrenci bulunmaktadır. Karbon ayak izi hesabının belirlenirken ilk olarak yüksekokulun toplam elektrik enerjisi tüketimi ve ısınma amaçlı kullanılan doğalgaz tüketimi ele alınmıştır. Bucak Sağlık Yüksekokulunun kullandığ 1 binada farklı bir yüksekokul daha bulunmaktadır. Elektrik enerjisi ve doğalgaz tüketimi ayrı faturalandırılmamaktadır. Bu nedenle elektrik enerjisi ve doğalgaz tüketimi için binanın toplam tüketim verileri alınmıştır. Elektrik tüketimi bina içerisinde bulunan aydınlatma, klima, ofislerde kullanılan araçlar ve asansörden kaynaklanmaktadır. Doğalgaz ise binanın 1sıtılması amaçlı kullanılmaktadır. İkinci olarak ise yüksekokul personeli ve öğrencilerin kullandığı araçlardan kaynaklı atık gazların oluşturduğu $\mathrm{CO}_{2}$ salınımdır. Salınım değerlerinin tespiti için birimlerde bulunan tüm personelin kullandığı araçların motor hacimleri ve günlük kat ettikleri mesafeler belirlenmiştir. Öğrencilerin kullandığ taşıma araçları için ise ilçe merkezi ile yüksekokul arasındaki mesafe kabul edilmiştir. Bu verilerin yanında tüm araçların aynı motor hacminde ve aynı yakıt kullanması durumundaki karbon ayak izindeki değişim Defra-Annex kriterlerine göre hesaplanmıştır Yüksekokula ait diğer salınım verileri Tablo1'de verilmiştir. Bu çalışmada, doğrudan ve dolaylı sera gazı salınımları üç kapsam altında incelenmiştir. Yüksekokulda 1sınma amaçlı kullanılan doğalgaz tüketimi kapsam 1 altında değerlendirilirken, toplam elektrik tüketimi kapsam 2 altında değerlendirilmiş, öğrencilerin ve tüm personelin ulaşımından kaynaklı salınım ise kapsam 3 altında değerlendirilmiştir. 
Tablo 1. Bucak Sağlık Yükssekokuluna ait diğer salınım verileri

\begin{tabular}{ll}
\hline Emisyon Kaynakları & Bucak Sağlık Yüksekokulu \\
\hline Öğrenci Sayısı & 357 \\
Personel Sayısı & 23 \\
Personel Araç Sayısı & 16 \\
Okulda Kullanılan Yakıt Türü & Doğalgaz \\
Dolmuş ile Öğrenci Taşıma Mesafesi & $2 \mathrm{~km}$ \\
Günlük Dolmuş Sefer Sayısı & $25-30 /$ gün \\
Dolmuş Yakıt Türü & Dizel \\
Diğer illerden Gelen Araç Sayısı & 7 \\
Okulun Bucak Merkeze Uzaklığı & $2 \mathrm{~km}$ \\
\hline
\end{tabular}

Bucak Sağlık Yüksekokulu salınım verilerine göre karbon ayak izi hesabı Tablo 3 ile Tablo13 arasında verilmiştir. Yüksekokulun kullandığı binaya ait toplam elektrik enerjisi tüketimi 2017 yılı için 114840 kWh'dir. Bucak Sağlık Yüksekokuluna ait salınım kaynakları verilerine göre karbon ayak izi hesabı aşağıdaki gibidir.

Bucak sağlık yüksekokulunun bünyesinde farklı bir yüksekokul daha bulunmaktadır. Bu nedenle binaya ait toplam tüketim değeri kullanılmıştır. Elektrik tüketiminden kaynaklı karbon salınım değeri Tablo 2'deki dönüşüm faktörleri verilmiştir [11,12]. 11 numaralı referanstaki dönüşüm parametrelerinden faydalanılarak Tablo 3'deki değerler hesaplamıştır.

Tablo 2. Elektrik Tüketimi Dönüşüm Faktörleri [11]

\begin{tabular}{cccccc}
\hline \multirow{2}{*}{ Ülkeler } & $\mathbf{1 9 9 0 - 2 0 0 9}$ & \multicolumn{3}{c}{ Elektrik Dönüştürme Faktörleri: } & $\mathbf{k g ~} \mathbf{C O}_{\mathbf{2}} \mathbf{~ k W h}$ Elektrik \\
\cline { 2 - 6 } Türkiye & 2005 & 2006 & 2007 & 2008 & 2009 \\
& 0.42638 & 0.43822 & 0.47821 & 0.49528 & 0.47993 \\
\hline
\end{tabular}

Tablo 3. Elektrik Tüketiminden Kaynaklanan $\mathrm{CO}_{2}$ Salınımı

\begin{tabular}{lcccccc}
\hline 2009 & \multicolumn{2}{c}{ Kapsam 2 } & \multicolumn{2}{c}{ Kapsam 3 } & \multicolumn{2}{c}{ Bütün Kapsamlar } \\
\cline { 2 - 7 } 5 Yıllık & \multicolumn{2}{c}{ Toplam Doğrudan } & \multicolumn{2}{c}{ Toplam Dolaylı Sera } & \multicolumn{2}{c}{ Genel Toplam Sera } \\
Ortalama & \multicolumn{2}{c}{ Sera Gazı } & \multicolumn{2}{c}{ Gazı } & \multicolumn{2}{c}{ Gazı } \\
kWh Yıllık & $\mathrm{kWh}$ & Toplam & $\mathrm{kWh} \mathrm{başına}$ & Toplam & $\mathrm{kWh}$ & Toplam \\
Tüketim & başına $\mathrm{kg}$ & $\mathrm{kg} \mathrm{CO}$ & $\mathrm{kg} \mathrm{CO}$ & $\mathrm{kg}$ & başına $\mathrm{kg}$ & $\mathrm{kg}$ \\
& $\mathrm{CO}_{2}$ & & & $\mathrm{CO}_{2} \mathrm{e}$ & $\mathrm{CO}_{2}$ & $\mathrm{CO}_{2} \mathrm{e}$ \\
Türkiye & 0.46360 & 53.240 & 0.06304 & 7.240 & 0.52664 & 60.479 \\
\hline
\end{tabular}

Tablo 4. Benzinli Araçlar ile Kat Edilen Mesafe

\begin{tabular}{lc}
\hline \multicolumn{1}{c}{ Karayolu yolcu taşıma dönüştürme faktörleri: Benzinli otomobiller } \\
\hline $\begin{array}{l}\text { Otomobil Türü } \\
\text { 1.4-2.0 litre arası motorlu benzinli } \\
\text { otomobiller }\end{array}$ & Toplam Yol $(\mathrm{km})$ \\
\hline
\end{tabular}


Tablo 5. Benzinli Araçlar ile Kat Edilen Mesafe

\begin{tabular}{|c|c|c|c|c|c|}
\hline \multicolumn{4}{|c|}{ Kapsam 1 veya Kapsam 3} & \multirow{2}{*}{$\begin{array}{c}\text { Kapsam } 3 \\
\text { Toplam } \\
\text { Dolaylı Sera } \\
\text { Gazı }\end{array}$} & $\begin{array}{c}\text { Tüm } \\
\text { Kansamlar }\end{array}$ \\
\hline $\mathrm{CO}_{2}$ & $\mathrm{CH}_{4}$ & $\mathrm{~N}_{2} \mathrm{O}$ & $\begin{array}{l}\text { Toplam } \\
\text { Doğrudan } \\
\text { Sera Gazı }\end{array}$ & & $\begin{array}{c}\text { Genel } \\
\text { Toplam } \\
\text { Sera Gazı }\end{array}$ \\
\hline $\begin{array}{l}\text { Toplam } \\
\text { kg CO}\end{array}$ & $\begin{array}{l}\text { Toplam } \\
\mathrm{kg} \mathrm{CO}_{2} \mathrm{e}\end{array}$ & $\begin{array}{l}\text { Toplam } \\
\mathrm{kg} \mathrm{CO}_{2} \mathrm{e}\end{array}$ & $\begin{array}{l}\text { Toplam } \\
\mathrm{kg} \mathrm{CO}_{2} \mathrm{e}\end{array}$ & $\begin{array}{l}\text { Toplam } \\
\mathrm{kg} \mathrm{CO}_{2} \mathrm{e}\end{array}$ & $\begin{array}{c}\text { Toplam } \\
\mathrm{kg} \mathrm{CO}_{2} \mathrm{e}\end{array}$ \\
\hline 3.111 & 2 & 10 & 3.123 & 626 & 3.749 \\
\hline
\end{tabular}

Personele ait verilen 1.4-2.0 litre arası motor hacmindeki benzinli otomobillerin aldıkları yıllık toplam yol verileri Tablo 4'de yer almaktadır. Bu verilere göre benzinli otomobillerden kaynaklı karbon salınım miktarı Tablo 5'dedir.

Tablo 6. Dizel Araçlar ile Kat Edilen Mesafe

\begin{tabular}{lc}
\hline \multicolumn{2}{c}{ Karayolu yolcu taşıma dönüştürme faktörleri: Dizel otomobiller } \\
\hline Otomobil Türü & Toplam Yol $(\mathrm{km})$ \\
$\mathbf{1 . 7}$ litre ve altı motorlu dizel otomobiller & 196480 \\
\hline
\end{tabular}

Tablo 7. Dizel Araçlardan Kaynaklanan $\mathrm{CO}_{2}$ Salınımı

\begin{tabular}{|c|c|c|c|c|c|}
\hline & \multicolumn{2}{|c|}{$\begin{array}{l}\text { Kapsam } 1 \text { veya } \\
\text { Kapsam } 3 \\
\end{array}$} & & Kapsam 3 & $\begin{array}{c}\text { Tüm } \\
\text { Kapsamlar }\end{array}$ \\
\hline $\mathrm{CO}_{2}$ & $\mathrm{CH}_{4}$ & $\mathrm{~N}_{2} \mathrm{O}$ & $\begin{array}{c}\text { Toplam } \\
\text { Doğrudan } \\
\text { Sera Gaz1 }\end{array}$ & $\begin{array}{c}\text { Toplam } \\
\text { Dolaylı } \\
\text { Sera Gazı }\end{array}$ & $\begin{array}{c}\text { Genel } \\
\text { Toplam } \\
\text { Sera Gazı }\end{array}$ \\
\hline $\begin{array}{l}\text { Toplam } \\
\text { kg COO }\end{array}$ & $\begin{array}{l}\text { Toplam } \\
\mathrm{kg} \mathrm{CO}_{2} \mathrm{e}\end{array}$ & $\begin{array}{l}\text { Toplam } \\
\mathrm{kg} \mathrm{CO}_{2} \mathrm{e}\end{array}$ & $\begin{array}{l}\text { Toplam } \\
\mathrm{kg} \mathrm{CO}_{2} \mathrm{e}\end{array}$ & $\begin{array}{l}\text { Toplam } \\
\mathrm{kg} \mathrm{CO}_{2} \mathrm{e}\end{array}$ & $\begin{array}{l}\text { Toplam } \\
\mathrm{kg} \mathrm{CO}_{2} \mathrm{e}\end{array}$ \\
\hline 27.733 & 10 & 348 & 28.091 & 5.580 & 33.671 \\
\hline
\end{tabular}

Personel dizel otomobillerinin aldıkları yıllık toplam yol Tablo 6' da verilmiştir. Buna göre dizel otomobillerin oluşturduğu karbon salınım miktarı Tablo 7'de yer almaktadır.

Tablo 8. LPG'li Araçlar ile Kat Edilen Mesafe

\begin{tabular}{lc}
\hline Karayolu yolcu taşıma dönüştürme faktörleri: Alternatif yakıtlı otomobiller \\
\hline Otomobil Türü & Toplam Yol (km) \\
LPG otomobil & 15040 \\
\hline
\end{tabular}


Tablo 9. LPG'li Araçlardan Kaynaklanan $\mathrm{CO}_{2}$ Salınımı

\begin{tabular}{|c|c|c|c|c|c|}
\hline \multicolumn{4}{|c|}{ Kapsam 1 veya Kapsam 3} & \multirow{2}{*}{$\begin{array}{c}\text { Kapsam } 3 \\
\text { Toplam } \\
\text { Dolaylı } \\
\text { Sera Gazı }\end{array}$} & \multirow{2}{*}{$\begin{array}{c}\begin{array}{c}\text { Tüm } \\
\text { Kapsamlar }\end{array} \\
\text { Genel } \\
\text { Toplam } \\
\text { Sera Gaz1 }\end{array}$} \\
\hline $\mathrm{CO}_{2}$ & $\mathrm{CH}_{4}$ & $\mathrm{~N}_{2} \mathrm{O}$ & $\begin{array}{l}\text { Toplam } \\
\text { Doğrudan } \\
\text { Sera Gazı }\end{array}$ & & \\
\hline $\begin{array}{l}\text { Toplam } \\
\text { kg CO }\end{array}$ & $\begin{array}{l}\text { Toplam } \\
\mathrm{kg} \mathrm{CO}_{2} \mathrm{e}\end{array}$ & $\begin{array}{l}\text { Toplam } \\
\mathrm{kg} \mathrm{CO}_{2} \mathrm{e}\end{array}$ & $\begin{array}{l}\text { Toplam } \\
\mathrm{kg} \mathrm{CO}_{2} \mathrm{e}\end{array}$ & $\begin{array}{l}\text { Toplam } \\
\mathrm{kg} \mathrm{CO}_{2} \mathrm{e}\end{array}$ & $\begin{array}{l}\text { Toplam } \\
\mathrm{kg} \mathrm{CO}_{2} \mathrm{e}\end{array}$ \\
\hline 2.833 & 6 & 20 & 2.859 & 355 & 3.214 \\
\hline
\end{tabular}

Personele ait LPG'li otomobillerin aldıkları yıllık toplam yol değeri Tablo 8'de verilmiştir. $\mathrm{Bu}$ değere göre personele ait LPG'li otomobillerden oluşan karbon salınım miktarı Tablo 9'dadır.

Tablo 10. Farklı Araçlar ile Kat Edilen Mesafe

\begin{tabular}{lc}
\hline Taksi, Otobüs, Demiryolu ve feribot yolcu taşımacılı̆̆ı dönüşüm faktörleri \\
\hline Otomobil Türü & Toplam Yol $(\mathrm{km})$ \\
Otobüs(Ortalama otobüs) & 85680 \\
\hline
\end{tabular}

Tablo 11. Farklı Araçlardan Kaynaklanan $\mathrm{CO}_{2}$ Salınımı

\begin{tabular}{cccccc}
\hline & Kapsam 1 veya Kapsam 3 & & Kapsam 3 & Tüm Kapsamlar \\
\hline $\mathbf{C O}_{2}$ & $\mathrm{CH}_{4}$ & $\mathrm{~N}_{2} \mathrm{O}$ & $\begin{array}{c}\text { Toplam } \\
\text { Doğrudan } \\
\text { Sera Gazı }\end{array}$ & $\begin{array}{c}\text { Toplam } \\
\text { Dolayl } \\
\text { Sera Gazi }\end{array}$ & Genel Toplam Sera Gaz1 \\
Toplam & Toplam & Toplam & Toplam & Toplam & Toplam \\
$\mathbf{k g ~ C O}$ & $\mathrm{kg} \mathrm{CO}_{2} \mathrm{e}$ & $\mathrm{kg} \mathrm{CO}_{2} \mathrm{e}$ & $\mathrm{kg} \mathrm{CO}_{2} \mathrm{e}$ & $\mathrm{kg} \mathrm{CO}_{2} \mathrm{e}$ & $\mathrm{kg} \mathrm{CO}_{2} \mathrm{e}$ \\
$\mathbf{9 . 5 0 8}$ & 10 & 74 & 9.592 & 2.019 & 11.611 \\
\hline
\end{tabular}

Öğrencilerin okula ulaşımları için kullandıkları otobüsün y1llık aldığı toplam yol Tablo10'da verilmiştir. Buna göre öğrenci ulaşımından oluşan karbon salınım Tablo11'de yer almaktadır.

Tablo 12. Farklı yakıt türlerinin bir enerjiye dönüştürülmesi

\begin{tabular}{cc}
\hline Yakıt türlerinin bir enerjiye dönüştürülmesi \\
\hline Yakıt Türü & Y1llık kullanılan miktar $(\mathrm{kWh}))$ \\
Doğalgaz & 512741.6 \\
\hline
\end{tabular}


Tablo 13. Doğalgazdan kaynaklanan $\mathrm{CO}_{2}$ Salınımı

\begin{tabular}{|c|c|c|c|c|c|}
\hline \multicolumn{4}{|c|}{ Kapsam 1 veya Kapsam 3} & \multirow{2}{*}{$\begin{array}{c}\text { Kapsam } 3 \\
\text { Toplam } \\
\text { Dolaylı } \\
\text { Sera Gazı }\end{array}$} & \multirow{2}{*}{$\begin{array}{c}\begin{array}{c}\text { Tüm } \\
\text { Kapsamlar }\end{array} \\
\text { Genel } \\
\text { Toplam } \\
\text { Sera Gazı }\end{array}$} \\
\hline $\mathrm{CO}_{2}$ & $\mathrm{CH}_{4}$ & $\mathrm{~N}_{2} \mathrm{O}$ & $\begin{array}{l}\text { Toplam } \\
\text { Doğrudan } \\
\text { Sera Gaz1 }\end{array}$ & & \\
\hline $\begin{array}{l}\text { Toplam } \\
\text { kg CO}\end{array}$ & $\begin{array}{c}\text { Toplam } \\
\mathrm{kg} \mathrm{CO}_{2} \mathrm{e}\end{array}$ & $\begin{array}{c}\text { Toplam } \\
\mathrm{kg} \mathrm{CO}_{2} \mathrm{e}\end{array}$ & $\begin{array}{l}\text { Toplam } \\
\mathrm{kg} \mathrm{CO}_{2} \mathrm{e}\end{array}$ & $\begin{array}{l}\text { Toplam } \\
\mathrm{kg} \mathrm{CO}_{2} \mathrm{e}\end{array}$ & $\begin{array}{l}\text { Toplam } \\
\mathrm{kg} \mathrm{CO}_{2} \mathrm{e}\end{array}$ \\
\hline 94.770 & 138 & 56 & 94.965 & 9.814 & 104.779 \\
\hline
\end{tabular}

Binanın 1sınma amaçlı tüketilen yıllık toplam doğalgaz miktarı Tablo 12 'de verilmiştir. Buna göre doğalgazdan dolayı oluşan salınım miktarı Tablo 13'de yer almaktadır. Personelin kullandığ 1 araçların her bir motor gücü ve yakıt türüne göre yıllık aldıkları mesafe değerleri ayrıntılı olarak Tablo 14'de verilmiştir.

Tablo 14. Motor Güçlerine Göre Kat Edilen Mesafe

\begin{tabular}{cc}
\hline Motor Gücü/Yakıt & $\begin{array}{l}\text { Yıllık Toplam Gidilen Mesafe } \\
(\mathbf{k m} / \mathbf{y} \mathbf{l})\end{array}$ \\
\hline 1.4 Benzin & 640 \\
1.6 Benzin & 14400 \\
1.4 Benzin-LPG & 640 \\
1.6 Benzin-LPG & 14400 \\
1.5 Dizel & 81280 \\
1.6 Dizel & 115200 \\
\hline
\end{tabular}

\section{Bulgular ve Tartışma}

Karbon ayak izi, insan aktiviteleri (ulaşım, elektrik tüketimi, su tüketimi, 1sınma, yakıt tüketimi vb.) gibi sonuçlardan oluşan sera gazı salınımlarının toplamından ibarettir. Sürdürülebilir bir çevre ve kalkınma için dünyada karbon salınımlarının az olduğu ekonomilere dönük adımlar atılmaktadır. Bu sebeple insan kaynaklı sera gazı salınımlarının azaltılması ve çevreye olan etkisini dengelemek için karbon ayak izi kavramı oluşturulmuştur [9].

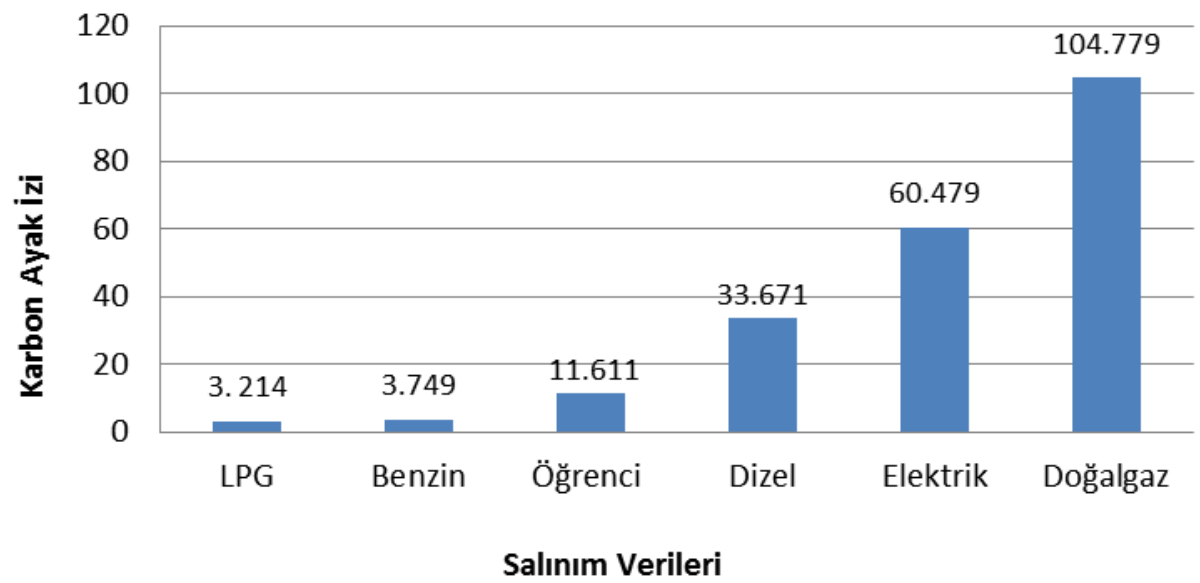

Şekil 2. Bucak Sağlık Yüksekokulu Karbon Ayak İzi 
Bucak Sağlık Yüksekokulu karbon salınım verilerine göre karbon ayak salınım dağılımları Şekil 2'de verilmiştir.

Bu çalışmada Burdur Mehmet Akif Ersoy Üniversitesi Bucak Sağlık Yüksekokulunun karbon ayak izi hesabı yapılmıştır. Hesaplama gerçekleştirilirken Kapsam1, Kapsam 2 ve Kapsam 3 olmak üzere üç parametrede değerlendirme yapılmıştır. Hesaplamada yıllık toplam elektrik tüketimi, yıllık toplam doğalgaz tüketimi, personel ve öğrencilerin ulaşımdan kaynaklı yakıt tüketimi gibi salınım verileri kullanılmıştır. Sonuçta Bucak Sağlık Yüksekokulunun yıllık karbon salınımı $217.503 \mathrm{CO}_{2} \mathrm{e}$ olarak bulunmuştur.

Bu hesaplamalardan farklı olarak yüksekokuldaki toplam personelin kullandığ 1 araçların aynı motor gücü ve yakıt türünde olması durumunda karbon salınımı benzinli araçlar için toplam $56.475 \mathrm{~kg}$, dizel araçlarda $38.826 \mathrm{~kg}$ ve LPG li araçlarda $48.423 \mathrm{~kg}$ olduğu görülmektedir. 1.6 litre motor gücü ve yakıt türüne göre karbon salınımlarının yüzdesel dağılımı Şekil 3'de verilmiştir.

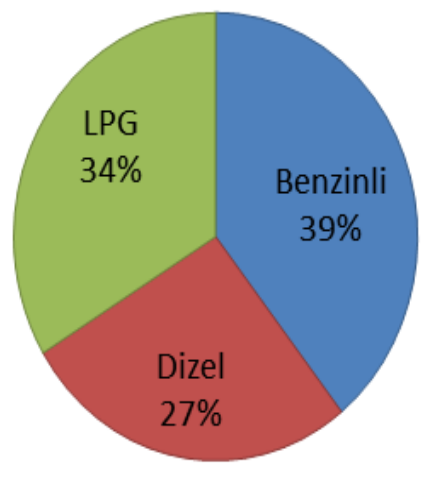

Şekil 3. Aynı Yakıt Türü ve Motor Hacmine Göre Karbon Salınımı

Yüksekokulun karbon salınımları dikkate alındığında 1sınma amaçlı kullanılan doğalgaz tüketiminin karbon salınımında en önemli etkiye sahip olduğu ve bunu sırasıyla elektrik tüketimi, dizel araçlar, öğrenci, benzin ve LPG takip etmektedir.

Sonuçta Bucak Sağlik Yüksekokuluna ait verilere göre doğalgaz, elektrik ve öğrenci ile personel ulaşımından kaynaklı toplam $\mathrm{CO}_{2} \mathrm{e}$ salınımı $217.503 \mathrm{~kg} / \mathrm{y} 1 \mathrm{l}$ 'dır. Personel ulaşımı için toplam kat edilen mesafe $226560 \mathrm{~km}$ 'dir. Araçların yakıt türü olarak benzin, dizel ve LPG kullanılmaktadır. Toplamda kat edilen mesafe benzinli araçlar ile yapıldığında karbon ayak izi $56.475 \mathrm{~kg} \mathrm{CO}_{2} \mathrm{e}$, dizel araçlarla yapıldığında $38.826 \mathrm{~kg} \mathrm{CO} 2 \mathrm{e}, \mathrm{LPG}$ 'li araçlar ile yapıldığında ise $48.423 \mathrm{~kg} \mathrm{CO} \mathrm{CO}_{2} \mathrm{e}$ olarak tespit edilmiştir.

Yüksekokulun bulunduğu bölgeyi düşündüğümüzde yenilenebilir enerji kaynaklarından güneş enerjisi potansiyelinin yüksek olması, fotovoltaik sistemlerle elektrik enerjisini ihtiyacının karşılanması mümkündür. Bu durum karbon salınımını azaltılması için önemli bir adım olacaktır.

\section{Sonuç ve Öneriler}

Bu çalışmada, Burdur Mehmet Akif Ersoy Üniversitesi Bucak Sağlık Yüksekokulunun karbon ayak izi tespit edilmiştir. Defra-Annex kriterleri kullanılarak tespit edilen karbon ayak izi hesabında yıllık olarak; 1sınma amaçlı kullanılan doğalgaz, elektrik tüketimi, öğrenci ve personel kaynaklı ulaşım gibi salınıma neden olan parametreler altında 2017 verileri kullanılmıştır. Karbon ayak izini azaltmaya yönelik alınacak tedbirler için oldukça önemlidir. 
Bucak Sağlık Yüksekokulunun doğalgaz, elektrik ve öğrenci ile personel ulaşımından kaynaklı toplam $\mathrm{CO}_{2} \mathrm{e}$ salınımı $217.503 \mathrm{~kg} / \mathrm{y}$ ll olarak bulunmuştur. Hesaplamalar sonucunda karbon salınımında en büyük etkinin ısınma amaçlı kullanılan doğalgaz tüketiminden kaynaklandığını ve bu sırasıyla elektrik tüketimi, dizel, benzin ve LPG'li araçlardan oluşan salınımlar takip etmektedir. Türkiye İstatistik Kurumu verilerine göre $\mathrm{CO}_{2}$ eşdeğeri 2016 toplam sera gazı emisyonu 1990'a göre \%135 artış göstermiştir. $\mathrm{CO}_{2}$ eşdeğer emisyonu 3,8 ton/kişi, 2016 yılında 6,3 ton/kişi olarak hesaplanmıştır [13].

Doğalgazdan tüketiminin sebep olduğu karbon salınımını engellemek için yenilenebilir enerji kaynaklarına yönelmeli, binalara 1sı yalıtımı yapılmalıdır. Elektrik tüketimi genel olarak 1sıtma, soğutma, ofis araçları ve asansör kullanımından kaynaklanmaktadır. Tasarruflu lambaların kullanılması, gereksiz ofis araçlarının kapatılması, verimliliği yüksek klimaların seçilmesi hem çevre hem de sağlığımız için asansör yerine merdivenlerin tercih edilmesi elektrik kaynaklı karbon salınımını azaltacaktır. Fotovoltaik güneş enerjisi sistemleri kullanılarak binanın kendi elektriğini kendi üretmesi için çalışmalar yapılmalıdır. Yakıt tüketiminden kaynaklanan salınımları azaltıcı düşük hacimli motorlar ve enerji tasarrufu sağlayıcı araçlar kullanılmalı, Personel ve öğrencilerin günlük kullandıkları mesafeler göz önünde bulundurularak minimum düzeyde enerji tüketimi sağlanmalıdır.

$\mathrm{Bu}$ veriler 1şığında yüksekokulda sürdürülebilir bir yaşam için çevre ve küresel ısınmadan kaynaklı oluşan iklim değişikliği önlemede karbon ayak izini düşürecek yeni tedbirler şu şekilde alınabilir;

- Çevre sorunları ve küresel iklim değişikliği ile ilgili farkındalık oluşturacak eğitim seminerleri düzenlenmeli ve projeler üretilmelidir.

- Yüksekokul bünyesinde bulunan programlarda çevre kirliliği, iklim değişiklikleri ve doğal kaynaklarımızın doğru kullanımına yönelik uygun seçmeli derslerin program müfredat içerisinde bulundurulması ve bu tür derslerin seçilmesi desteklenmelidir.

- Karbon salınımını azaltmaya yönelik düzenli bir şekilde yıllık ağaçlandırma çalışmaları yapilmalidır.

- Çevresel ürünler ve geri dönüşümlü malzeme kullanımını yaygın hale getirecek projeler düzenlenmelidir.

- Karbon ayak izini etkileyen su, doğalgaz, atık, elektrik, 1sınma, ulaşım gibi konularda tasarrufa gidilmelidir.

- Alternatif enerji kaynaklarının kullanımı teşvik edilmeli ve bu alana yönelik çalışmalar hızlandırılmalıdır. Kamu kurumları kendi elektriğini kendi üretecek hale gelmelidir.

Önerilen bu çalışmalar sayesinde Burdur Mehmet Akif Ersoy Üniversitesi Bucak Sağlik Yüksekokulunun karbon ayak izi azaltılmış ve gelecekte nesillerin çevre bilincine sahip birer bireyler olması için önemli adım atılmış olacaktır.

\section{Kaynaklar}

[1] Rana R., Ingrao C., Lombardi M., Tricase C., "GreenhouseGas Emissions Of An Agro-Biogas Energy System: Estimation Under The Renewable Energy Directive”, Science of The Total Environment, 2016, 550:1182-1195.

[2] Özçelik G. "Çanakkale Onsekiz Mart Üniversitesi Terzioğlu Kampüsü’nün Enerji ve Karbon Ayak İzi Açısından Değerlendirilmesi”, Yüksek Lisans Tezi, Çanakkale Onsekiz Mart Üniversitesi, Fen Bilimleri Enstitüsü, 76 sayfa, (2017).

[3] Bonamente E., Pelliccia L., Merico C.M., The Multifunctional Environmental Energy Tower: Carbon Footprint and Land Use Analysis of an Integrated Renewable Energy Plant, Sustainability, 2015, 7: 13564-13584. 
[4] Güller S., "Muğla Evsel Atıksu Arıtma Tesisi Karbon Ayak İzinin Değerlendirilmesi”, Yüksek Lisans Tezi, Muğla Sitkı Koçman Üniversitesi, Fen Bilimleri Enstitüsü, 90 sayfa, (2018).

[5] Letete T.C.M., Mungwe N.W., Guma M., Marquard A.,. Carbon footprint of the University of Cape Town. Journal of Energy in Southern Africa, 2011, 22(2): 2-12.

[6] Aroonsrimorakot S., Yuwareeb C., Arunlertareeb C., Hutajareornb R., Buaditb T., Carbon Footprint of Faculty of Environment and Resource Studies, Mahidol University, Salaya Campus. Science direct APCBEE Procedia, 2013, 5:175-180.

[7] Turanlı A.M., Estimation of Carbon Footprint: A Case Study For Middle East Technical University, Yüksek Lisans Tezi, Ortadoğu Teknik Üniversitesi, 122 sayfa, (2015).

[8] Sreng R., Gümrükçüoğlu Yigit M., Carbon footprint studies on Esentepe Campus of Sakarya University, Turkey in 2015, Sakarya Üniversitesi Fen Bilimleri Enstitüsü Dergisi, 2017, 21(5): 1095-1099.

[9] Binboğa G., Ünal A., Sürdürülebilirlik Ekseninde Manisa Celal Bayar Üniversitesi'nin Karbon Ayak İzinin Hesaplanmasına Yönelik Bir Araştırma, Uluslararası İktisadi ve İdari İncelemeler Dergisi, 2018, 21:187-202.

[10] Kaypak Ş., "Ekolojik Ayak İzinden Çevre Barışına Bakmak”, Türk Bilimsel Derlemeler Dergisi, 2013,6 (1),154-159.

[11] https://ghgprotocol.org/calculation-tools (07.11.2018)

[12] Yaka İ. F., Koçer A., Güngör A.,“Akdeniz Üniversitesi Sağlık Hizmetleri Meslek Yüksekokulu Karbon Ayak İzinin Tespiti”, Makine Teknolojileri Elektronik Dergisi, 2015, 12(3) . 37-45.

[13] http://www.tuik.gov.tr/PreHaberBultenleri.doid=27675, (06.11.2018). 